


\title{
To laugh or not to laugh? That is the question.
}

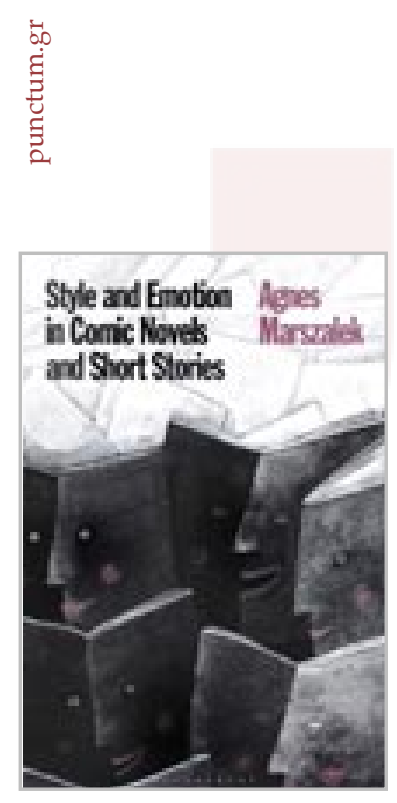

\author{
BY: Villy Tsakona
}

Marszalek, Agnes, 2020

\section{Style and Emotion in Comic Novels and Short Stories}

London: Bloomsbury Academic. 171 pp. £65 (Hbk, ISBN 9781350054585 , epub/Mobi, eBook ISBN 9781350054608, pdf/ ebook ISBN 9781350054592)

W

e usually think of comedy and tragedy as opposites, but perhaps we should consider them as two sides of the same coin. As Morreall (1999: 21) suggests, "[ $t$ ]he most basic belief [which the comic and the tragic visions of life] share is that life is full of incongruities, discrepancies between the way things ought to be and the way they are. The difference between the two visions of life is more in their attitudes than in any beliefs about matters of fact." They involve different and usually opposite ways of evaluating the same human condition. In other words, comedy and tragedy are built on incongruities assessed and framed to generate positive and negative emotions, respectively. Furthermore, comic/humorous and tragic/serious elements may co-occur in the same text, even if the text is primarily intended as funny. In such cases, texts become a blend of humorous utterances/parts and serious or even tragic ones - the latter constitute what Attardo (2001: 89) calls serious relief in humorous texts.

ARTICLE INFO:

\section{Volume: 06}

Issue: 02:2020

Month: March

ISSN: 2459-2943

DOI: 10.18680/hss.2020.0033

Pages: 261-264

Lic.: CC BY-NC-ND 4.0
There is relatively little research regarding the interplay between comedy and tragedy and the co-occurrence of humorous and serious comedy parts. In exploring these two topics, Agnes Marszalek makes a significant contribution in addressing this gap. More specifically, she aims to demonstrate how comic narratives may not only amuse but also provoke emotions like anxiety, suspense, embarrassment, and distress. Having a robust interdisciplinary perspective that draws on linguistics, psychology, philosophy, and literary/film/ televi- 
sion studies, she studies a corpus of English comic novels and short stories of diverse styles and authors, written over quite a long period (1889-2008).

Chapter 1 presents the main concepts used in the analyses to follow. More specifically, the author defines comic narratives as texts relying on "specific stylistic devices that direct our emotional experience in order to entertain us" (p. 1). Such texts contain narrative worlds, namely "imaginary spaces built partly from the linguistic elements present in the text and partly from the readers' knowledge and cognitive mechanisms" (p. 1). In comic narratives, the constructed narrative worlds are humorous worlds, which "elicit an overall impression of humor in the reader - an impression which can enhance the humorous potential of the individual elements that appear in the world" (p. 5). Their stability depends on stylistic cues causing the opposite effects of distance or immersion: the first one is associated with humor creation and the latter with the disruption of humor experience.

In Chapter 2, the theoretical background of the study emerges more clearly. The author discusses how a narrative's words enable the reader to construct a narrative world (see above). Since texts generate (positive or negative) emotional judgments and feelings, such as empathy, suspense, and curiosity, the narrative world is explored not only as a mental but also as an emotional construct. The chapter also discusses humor's main theories, especially incongruity theory (see Morreall 1999 above), utilized in the book's analytical part.

In Chapter 3, Marszalek investigates the mixing and balancing of humorous and non-humorous parts in comic narratives. She proposes that comic writers adjust readers' expectations by establishing a humorous mode, i.e., a "cognitive state that facilitates a humorous interpretation" (p. 33). It is a mode intended to create a humorous mood, i.e., the "affective state that predisposes us towards experiencing the emotion of amusement" (p. 33). This is achieved through paratexts (e.g., cover design, titles, blurbs, book review extracts on the book cover, prologues) and comic narratives' openings. The author also investigates the stylistic cues comic writers employ to shift from the humorous mode/mood to the non-humorous one. The stabilizing/distancing cues invite and allow readers to laugh with/at the narrated events. In contrast, the destabilizing/engaging ones disrupt the humorous mode/mood and yield "complex humorous responses" (p.48), combining amusement with negative, unpleasant emotions. Thus, comic narratives turn out to blend entirely opposed modes/moods.

Chapter 4 investigates the categories of stabilizing and destabilizing cues as resources for characterization in comic narratives. Characterization in combination with humor may trigger three primary emotions: sympathy, empathy, and identification. The author draws on Northrop Frye's (1957) four comic character types - self-deprecator/ eiron, impostor/alazon, buffoon/bomolochoi, churl/agroikos - and their merging in the misfit figure to account for instances of stereotyping, miscommunication, impolite- 
ness, and social disruption; all of them familiar sources of humor in comic narratives. Marszalek uses these concepts in different combinations to show how different character configurations and narrated events (de)stabilize the prevailing humorous mode/mood in the texts examined.

Chapter 5 continues and completes the analysis of (de)stabilizing cues in comic narratives. This time, Marszalek focuses on how story structure, the order of the narrated events, and the amount of information disclosed may provoke either amusement or complex humorous responses, including negative emotions. On the one hand, stabilizing cues such as foreshadowing, comical complications, and their resolution make readers expect the unexpected, usually leading to a happy ending. The author underlines the significance of readers' familiarity with comedy as a genre: knowing that a happy end will eventually occur, they look forward to the heroes' overcoming of all accidents or obstacles. On the other hand, destabilizing cues such as (comic) suspense, dramatic irony, and recurrence make readers bear the unbearable. They manage to endure the problematic or even painful plot events' negative emotional impact on them and not lose sight of the prevailing humorous mode/mood.

Chapter 6, finally, outlines the study's findings and summarizes them in a threepage table, which is especially helpful to researchers wishing to apply the author's analytical model.

Marszalek's style and argumentation are clear and persuasive, while the examples she discusses are well-chosen and analyzed in great detail. The author also elaborates on subtle differences between overlapping notions (e.g., suspense/surprise, repetition/ recurrence, comic events / gags). An essential asset of the book is that the author's analyses are complemented and confirmed by actual readers' comments of the books comprising the corpus. The author collected them from publicly accessible online sources. Unfortunately, these comments are used rather sparingly in the analysis. Ideally, they could provide more diverse interpretations of the books examined to illustrate, among other things, whether readers shift modes/moods while reading, as proposed by the author (on the methodological significance of analyzing authentic and spontaneous reactions to humor, see Tsakona 2020).

The book is highly recommended to scholars from a wide range of disciplines (linguistics, literary studies, semiotics, narratology, cultural studies, media studies, to name but a few) interested in the overlap and fuzziness between comedy and tragedy, humor and seriousness. It paves the way for more research to shed light on the interplay between comedy and tragedy and between the humorous and non-humorous/serious aspects of the same text. Such research would eventually offer more sophisticated analytical tools, which would help us account for the diverse or even opposing reactions to texts intended as humorous, especially in cases where some readers do not reach a humorous interpretation. 


\title{
References
}

Attardo, Salvatore 2001. Humorous Texts: A Semantic and Pragmatic Analysis. Berlin: De Gruyter Mouton.

Frye, Northrop 1975. Anatomy of Criticism: Four Essays. Princeton: Princeton University Press.

Morreall, John 1999. Comedy, Tragedy, and Religion. Albany: State University of New York Press.

Tsakona, Villy 2020. Recontextualizing Humor: Rethinking the Analysis and Teaching of Humor. Boston: De Gruyter Mouton.

\author{
AUTHOR \\ Villy Tsakona Associate Professor of Social and Educa- \\ tional Approaches to Language, Department of Early \\ Childhood Education, National and Kapodistrian Uni- \\ versity of Athens, Greece.
}




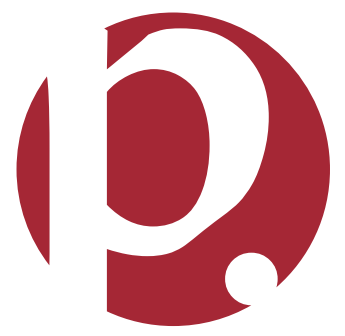

